\title{
Promoting Active Transport in Students' Travel Behavior: A Case from Yogyakarta (Indonesia)
}

\author{
Muhammad Zudhy Irawan (Corresponding author) \\ Graduate School of Engineering, Kyushu University \\ 744, Motooka, Nishi-ku, Fukuoka, Japan, 819-0395 \\ Tel: 81-92-802-3403 E-mail: irawan@civil.doc.kyushu-u.ac.jp \\ Tomonori Sumi \\ Graduate School of Engineering, Kyushu University \\ 744, Motooka, Nishi-ku, Fukuoka, Japan, 819-0395 \\ Tel: 81-92-802-3403E-mail: sumi@doc.kyushu-u.ac.jp
}

\begin{abstract}
School active commute has decreased in the last few decades. This occurrence resulted not only in increasing congestion and pollution, but also in decreasing children's physical health. This study aims to understand students' travel behavior on school commute by finding the factors influencing travel mode choice. A multinomial logit model was used to explain the students' travel behavior in Yogyakarta, a city which is dominated by motorcyclists. A number of 878 students were selected classifying into children (6-12 years old) and adolescents (13-18 years old). Empirical results showed that distance from home to school is the critical factor in determining active commute. However, factors of age, gender, and characteristics of students' household also play an important role in shaping students' travel behavior. Finally, to revive active commute, several appropriate policies such as bike to school program or synchronization of work and school start/end time were proposed in this study.
\end{abstract}

Keywords: Travel behavior, Active commute, Mode choice, Students

\section{Introduction}

The development of sustainable transportation is always associated with transport policy and technology, where it aims to minimize environment impact caused by motor vehicles such as congestion, air pollution, and noise. The design of vehicle free city planning and making environmentally-friendly vehicles are some actions taken toward a sustainable transport in the future.

However, by the low impact on the environment produced, promoting an active transport is an easy way to pursue that goal for the present. According to Litman (2003), walking, cycling, skating, and manual wheelchairs were classified into definitions of active transport in regards to means of transportation moved by human power. Further, trips using public transport were also considered within active transport due to walking on access or egress roads (National Public Health Partnerships, 2001).

Unfortunately, several countries have suffered significant decline of active transport in the last few decades. For instance, in the United Stated, walking has decreased from $9.35 \%$ of all trips in 1969 to $8.6 \%$ of all trips in 2001 (Florida Department of Transportation and Center for Urban Transportation Research, 2006). A decrease in active transport is also indicated by a sharp increase of motor vehicles ownership. According to the Federal Highway Administration, the number of motor vehicles in United Stated steadily increases in each year since 1960 except in 1991 and 1998 (Federal Highway Administration, 2003).

The dependency of private vehicle use has spread out to the children's travel behavior. McDonald (2007) found that a significant increase of students using automobiles either escorted or self driven has occurred from $17 \%$ in 1969 to $55 \%$ in 2003. In fact, the population of children has been increasing since the last few decades (Ewing et al., 2004; United States Census Bureau, 2005). These occasions give a tendency to private motor vehicle use in the future, and therefore it is contrary to the principle of development of sustainable transportation which is expected for people to take public transports, walk, or cycle in their daily travels.

In Indonesia, the similar condition has been occurring. Motor vehicles especially motorcycles sharply increase in every year. Indonesia Ministry of Transportation recorded that private vehicles have risen 74.95 percent in just four years. This situation directly impacts on high number of traffic accidents. In 2008, there were 91,598 traffic 
accident casualties or increase 429 percent from the previous five years. People aged 15-25 years old have the highest percentage due to accident casualties on the road (Indonesia Ministry of Transportation, 2008).

This study aims to understand the children's travel behavior regarding to school commute in Yogyakarta, Indonesia. Specifically, we examine the relationship between travel mode and the factors that might influence mode choice. By understanding their behaviors, we thus can find various rigorous policies to promote school active commute based on the empirical results. Obviously, since the groups of population aged 5-9, 10-14, and 15-19 years old are three largest respectively based on five year groupings (Indonesia Central Bureau of Statistics, 2005), children's trips are predicted have a significant contribution on traffic congestion. By promoting active transport on children's travel behavior, we not only reduce traffic congestion and pollution, but also increase the physical fitness (Oja et al., 1998) and prevent children obesity (Fox, 2004).

The city of Yogyakarta was selected as a study area regarding the centre of education in Indonesia. As shown in Figure 1, there are 349 schools within Yogyakarta, which consists of 184 elementary schools, 64 junior high schools, and 61 senior high schools (Yogyakarta Statistical Agency, 2007). Students in those levels of school were chosen as respondents. However, considering the different travel behaviors between children and adolescents, particularly relating to parental intervention in determining travel mode to/from school, we thus classified the respondents into two different groups: students aged 6-12 years old were categorized as children and students aged 13-18 years old were categorized as adolescents.

\section{Literature Review}

Even though the studies on children's travel behavior are intensively researched lately, most of these studies focused travel mode choice on whether using bicycle or walk (Everson et al., 2003; Hume et al., 2009). Also, policies proposed to promote active transport to school still remain on walking and biking transport modes (Staunton et al., 2003).

In its development, several studies have considered alternative transport modes (e.g. private vehicles, school buses, public transports) and the effect of household characteristics such as factors of income and number of private motor vehicles ownership into children's travel mode (DiGuiseppi et al., 1998; Vovsha and Petersen, 2005). However, only a few studies that examine more deeply about the characteristics of each household member. For instance, whether or not there is an influence of the number of employees with designated start time at workplace or the number of school going children in a household on children's travel mode choice to school.

More importantly, in regards to private motor vehicle as an alternative mode to/from school, several previous studies examined that identified private motor vehicles are car (Muller et al., 2008; Fyhri and Hjorthol, 2009; Zwerts et al., 2009).Therefore, children from low income household tend to do active transport due to private car unavailability (McMillan, 2006; McDonald, 2008). Meanwhile in eastern Asian countries, it is clear that motorcycle plays an important role in daily life even though it is not popular in western countries (Hsu et al., 2003; Chang and $\mathrm{Wu}, 2008$ ). By the motorcycle's affordable price, it will be easier for children from low income household to use this transport means as an alternative mode to school.

Therefore, considering the above mentioned, we also attempt to solve the major gaps from previous researches in achieving the objective of this study.

\section{Methodology}

\subsection{Questionnaire Survey}

A questionnaire survey was carried out from March to May 2009 in several schools in Yogyakarta. Out of 1,362 randomly distributed forms, 878 forms $(64.46 \%)$ were recollected effectively. The surveying items consist of two main parts, those are: 1) individual information, such as age, gender, home address, driving license ownership, and transport means to and from school, 2) characteristics of household, such as: number of private vehicles ownership, number of school going children, and characteristics of family members in a household. As a result, a basic descriptive statistic and travel mode to/from school are shown in Table 1 and Table 2 respectively.

A number of 472 children and 406 adolescents participated in this survey. There were seven alternatives on modes combination to and from school. Escorted by family members became the highest students' travel mode choice. Many students prefer to be escorted by family members particularly on travel to school. From 58.66 percent of students escorted to school and 43.85 percent of students picked up at school, there were only $3.69 \%$ and $3.38 \%$ of escorted students were chauffeured by cars on trip to and from school respectively, whereas the rest were chauffeured by motorcycles. 


\subsection{Proposed Model}

A multinomial logit model was used to find the factors influencing students' travel modes choice. This model assumes that a person will choose a choice which has the highest utility value (McFadden, 1981). Suppose that the utility of a mode $(i)$ chosen by person $n$ between the other modes $(j)$ is given by:

$$
U_{n i}=\alpha_{i}+\beta X_{n i}+\varepsilon_{n i}
$$

Where, $\alpha$ represents a vector of constants of mode $i, \beta$ indicates a vector of coefficients defining the utilities of mode $i, X_{n i}$ is a vector of explanatory variables on mode $i$ by traveler $n$, and $\varepsilon_{n i}$ shows an extreme-value error vector specific to mode $i$ by traveler $n$.

In this study, the explanatory variables consist of characteristics of students (age, gender, and driving license ownership), characteristics of households (number of vehicles ownership, number of school-going children), characteristics of family members (number of family members with designated work start/end time), and distance from home to school.

Then, by assuming $\varepsilon_{n i}$ is independently and identically gumbel distributed among other choice travel mode, the probability of mode $i$ chosen by traveler $n$ is expressed by:

$$
P_{n i}=\exp \left(U_{n i}\right) / \sum_{i \in j} \exp \left(U_{n j}\right)
$$

The coefficients can be estimated by maximizing the log likelihood function as shown below.

$$
L L=\sum_{n=1}^{N} \sum_{i \in j} \theta_{n i} \ln \left(P_{n i}\right)
$$

Where $\theta_{n i}$ is equal to 1 if traveler $n$ chooses mode $i$ and 0 if otherwise.

\section{Result and Discussion}

Applying the above proposed model, the estimated coefficients of explanatory variables are shown in Table 3 and Table 4. It should be noted that motorcycle mode and escorted by parents/family members were treated as reference points for adolescents' and children's trip behaviors respectively. Then, the utilities of other modes were modeled relative to the base mode.

\subsection{Characteristics of Students}

Looking into the factor of gender, there were no reciprocal relationships on children's and adolescents' trips to school by walk, bicycle, or take the buses. The similar result occurred on travel from school except on children walking and taking the buses. On these two modes, positive correlations were found showing boys are more likely to walk or take the buses from school than picked up at school.

Relating to the factor of age, a positive relationship occurred on children walking, biking, and taking the buses from school. Meanwhile, on travel to school, the similar result only occurred on bicycle mode choice. It shows that younger children tend to be escorted by family members than use those modes. Perhaps, parental fears in respect to the children's maturity and capability in overcoming vehicle traffic flow are one of the reasons of these circumstances. Therefore, a safe route to/from school program by providing sidewalks or special lanes for bicyclists is predicted can stimulate children in active commute.

In term of adolescents' travel behaviors, negative correlations were found both on travel to and from school in all travel modes, meaning older adolescents have a propensity to self driven. This phenomenon can be connected with driving license ownership factor, which shows a positive correlation on motorcycle use. When an adolescent is old enough to obtain driving license, he/she absolutely chooses motorcycle as his/her travel mode on school commute. However, girls have a tendency to be escorted by family members than self driven due to parental fears. As a result, an increase on minimum age to obtain the driving license can effectively shift to active transport means both on travels to and from school.

\subsection{Characteristics of Households}

Except on children walking and cycling to school, the presence of multiple vehicles in a household affects on private vehicle mode choice. The more vehicles owned in a household, the more possibility for students to use private vehicle either escorted or self driven. Meanwhile, in term of children walking and cycling to school, uncorrelated variables between private motor vehicle ownership and active transport to school showed that children have a dependence to be chauffeured to school by motorcycle mode. This result gives a different behaviour on children's travel mode choice compared to several previous researches, where the identified private motor vehicles are car (see: McMillan et al., 2006; Ewing et al., 2004; Braza et al., 2004). 
The existence of multiple school-going children only influence on children's travel mode choice by bicycle. In this case, a negative correlation was found showing children from a household with multiple school-going children are less likely to be escorted to/ from school.

\subsection{Characteristics of Family Members}

Designated work end time has a positive impact to all travel modes choice by children, meaning that parents or family members are less liable to pick their children up at school due to parents' unfinished working time. Meanwhile, there was a positive relationship in adolescents' travel behavior relates to parental escort, showing that parents or family members with designated work start time incline to set out to work jointly with their children or siblings who are high school students. Probably, it reflects the convenience to synchronize students' and workers' departure time. Hence, a synchronization of work and school start/end time is predicted can reduce the possibility to self driven on adolescents' travel behavior.

\subsection{Distance}

As shown by negative values in active transport modes, the tendency of students in active commute will decline due to the increasing of distance from home to school. Walking has a much higher sensitivity compared to the other active transport means, mainly on travel to school. Consequently, it will be difficult to promote "walk to school" program. Other programs such as "bike to school" can be chosen as an alternative in promoting active school commute. Instead reducing air pollution level, this program also can be a barrier to motorcycle use.

\section{Conclusion}

This paper revealed the factors influencing students' travel behaviors in mode choice due to decreasing active commute in the last few decades in Yogyakarta, Indonesia. Several appropriate policies are then proposed in this study to promote active transport and reduce the motorcycle use.

Empirical results showed that students' travel mode to/from school is highly influenced by students' inherent characteristics. For instance, older students tend to walk, bike, or take the buses on school commute. Meanwhile, boys are less likely to be escorted in case of travel from school. However, driving license ownership and distance are the most influence factors in shaping students' travel behavior whether or not students do active commute. On the other hand, characteristics of students' household, such as the number of vehicles ownership and the number of school-going children in a household also contributed in determining students' travel behavior. The more private vehicles are owned in a household, the less possibility for students to walk, cycle, or use the buses to/from school. Meanwhile, in term of family members' characteristics, designated start/end time at workplace also impacted on students' travel mode choice. Many adolescents are escorted to school by family members on the way to office.

Finally, several proposed policies such as providing sidewalks and bicycle special lanes, increasing the minimum age in obtaining a driving license, synchronizing work start/end time and adolescent's school start/end time, and bike to school program are useful programs to promote school active commute and pursue a sustainable transport in Yogyakarta, Indonesia.

\section{References}

Braza, M., Shoemaker, W., and Seeley, A. (2004). Neighbourhood design and rates of walking and biking to elementary school in 34 California communities. American Journal of Health Promotion, 19, 128-136.

Central Bureau of Statistic (2005). Statistics of Indonesia: Number of population by age and group for 2005, [online] Available $\leq \mathrm{http}: / /$ www.datastatistik-indonesia.com/component/option,com_tabel/kat,1/idtabel,116/Itemid $\geq \quad$ (Accessed: 22th March 2010).

Chang H.L. and Wu, S.C. (2008). Exploring the vehicle dependence behind mode choice: Evidence of motorcycle dependence in Taipei. Transportation Research Part A, 42, 307-320.

DiGuiseppi, C., Roberts, I., and Li, L. (1998). Determinants of car travel on daily journeys to school: cross sectional survey of primary school children. Br. Med. Journal, 316, 1426-1428.

Evenson, K.R., Huston, S.L., McMillen, B.J., Bors, P., and Ward, D.S. (2003). Statewide prevalence and correlates of walking and biking to school. Arch. Pediatr. Adolesc. Med., 157, 887-892.

Ewing, R., Schroeer, W., and Greene, W. (2004). School Location and Student Travel: Analysis of Factors Affecting Mode Choice. Transportation Research Record, 1895, 55-63. 
Federal Highway Administration. (2003). Highway Statistics in 2003, [online] Available: $\leq \mathrm{http}: / /$ www.fhwa.dot.gov $\geq$ (Accessed: 28th September 2010).

Florida Department of Transportation and Center for Urban Transportation Research (2006). Transportation System: Bike and Pedestrian. Florida.

Fox, K.R. (2004). Childhood obesity and the role of physical activity. Journal of the Royal Society for the Promotion of Health, 124, 34-39.

Fyhri, A. and Hjorthol, R. (2009). Children's independent mobility to school, friends and leisure activities. Journal of Transport Geography, 17, 377-384.

Hsu, T.P., Sadullah, A.F.M., and Nguyen, X.D. (2003). A Comparison Study on Motorcycle Traffic Development in Some Asian Countries - Case of Taiwan, Malaysia, and Vietnam.

Hume, C., Timperio, A., Salmon, J., Carver, A., Giles-Corti, B., and Crawford, D. (2009). Walking and cycling to school: Predictors of increases among children and adolescents. American Journal of Preventive Medicine, 36, 195-200.

Indonesia Ministry of Transportation. (2008). Transportation statistics, Book 12008 Edition, [online] Available: $\leq$ http://www.dephub.go.id/files/media/file/statistik-perhubungan-2008.pdf $\geq$ (Accessed: 22th March 2010).

Litman, T. (2003). Integrating public health objectives in transportation decision making, The Science of Health Promotion, 18, 103-108.

McDonald, N.C. (2007). Active transportation to school: Trends among U.S. schoolchildren, 1961-2001. American Journal of Preventive Medicine, 32, 509-516.

McDonald, N.C. (2008). Critical factors for active transportation to school among low-income and minority student: Evidence from the 2001 national household travel survey, American Journal of Preventive Medicine, 32, 509-516.

McFadden, D. (1981). Structural Analysis of Discrete Data with Econometrics Applications (pp. 198-272), Cambridge: MIT Press

McMillan, T.E., Day, K., Boarnet, M., Alfonzo, M., and Anderson, C. (2006). Johnny walks to school - Does Jane? Sex differences in children's active travel to school. Children, Youth and Environments, 16, 75-89

McMillan, T.E. (2007). The relative influence of urban form on a child's travel mode to school. Transportation Research Part A, 41, 69-79.

Muller, S., Tscharaktschiew, S., and Haase, K. (2008). Travel-to-school mode choice modelling and patterns of school choice in urban areas, Journal of Transport Geography, 16, 342-357.

National Public Health Partnership. (2001). Promoting active transport: an intervention portfolio to increase physical activity as a means of transport, Melbourne.

Oja, P., Vuori, I., and Paronen, O. (1998). Daily walking and cycling to work: their utility as health-enhancing physical activity. Patient Education and Counseling, 33, S87-S94.

Staunton, C.E., Hubsmith, D., and Kallins, W. (2003). Promoting safe walking and biking to school: The Marin Country success story. American Journal of Public Health, 93, 1431-1434.

United States Census Bureau. (2005). School Enrolment - Social and Economic Characteristics of Students: October 2005, [online] Available: <http://www.census.gov/prod/2005pubs/p20-554.pdf $>$ (Accessed: 15th October 2010).

Vovsha, P. and Petersen, E. (2005). Escorting children to school: statistical analysis and applied modelling approach. Transportation Research Record, 1921, 131-140.

Yogyakarta Statistical Agency (2007). Yogyakarta in Number: Chapter 4, [online] Available: $<$ http://yogyakarta.bps.go.id/component/content/article/58-sosial/70-sosial> (Accessed: 8th July 2010).

Zwerts, E., Allaert, G., Janssens, D., Wets, G., and Witlox, F. (2009). How children view their travel behaviour: a case study from Flanders (Belgium). Journal of Transport Geography, 18, 702-710. 
Table 1 . Statistic of the explanatory variables

\begin{tabular}{|c|c|c|c|}
\hline \multirow{2}{*}{ Explanatory Variables } & \multirow{2}{*}{ Description } & \multicolumn{2}{|l|}{ Mean (std) } \\
\hline & & Children & Adolescents \\
\hline \multicolumn{4}{|c|}{ Characteristics of Students } \\
\hline 1. $\quad$ Age & Student's age & $9.157(1.526)$ & $16.397(1.518)$ \\
\hline 2. $\quad$ Gender (Male) & Dummy, 1 if male & $0.436(0.496)$ & $0.404(0.491)$ \\
\hline 3. Driving License & Dummy, 1 if owning & - & $0.401(0.491)$ \\
\hline \multicolumn{4}{|c|}{ Characteristics of Households } \\
\hline $\begin{array}{l}\text { 1. Number of } \\
\text { vehicles }\end{array}$ & $\begin{array}{l}\text { Number of cars and } \\
\text { motorcycles in a household }\end{array}$ & $2.303(1.149)$ & $2.522(1.362)$ \\
\hline $\begin{array}{l}2 . \quad \text { Number of } \\
\text { school going children }\end{array}$ & $\begin{array}{l}\text { Number of students in a } \\
\text { household }\end{array}$ & $2.127(0.785)$ & $1.52(0.611)$ \\
\hline $\begin{array}{l}\text { Characteristics of } \\
\text { Family Members }\end{array}$ & $\begin{array}{l}\text { Number of family members } \\
\text { with designated work start } \\
\text { and end time }\end{array}$ & $1.290(0.802)$ & $1.264(0.97)$ \\
\hline Distance & In kilometer & $3.029(2.564)$ & $5.187(3.434)$ \\
\hline
\end{tabular}

Table 2. Travel mode choice

\begin{tabular}{|c|c|c|c|c|c|c|c|}
\hline & \multicolumn{6}{|c|}{ Travel Modes From School } \\
\hline & & Walking & Bicycle & Motorcycle & Escorted & Bus & Total \\
\hline \multirow{6}{*}{ 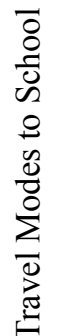 } & Walking & 7.4 & & & & & 7.4 \\
\hline & Bicycle & & 7.97 & & & & 7.97 \\
\hline & Motorcycle & & & 18.91 & & & 18.91 \\
\hline & Escorted & 3.08 & & & 43.85 & 11.73 & 58.66 \\
\hline & Bus & & & & & 7.06 & 7.06 \\
\hline & Total & 10.48 & 7.97 & 18.91 & 43.85 & 18.79 & 100 \\
\hline
\end{tabular}




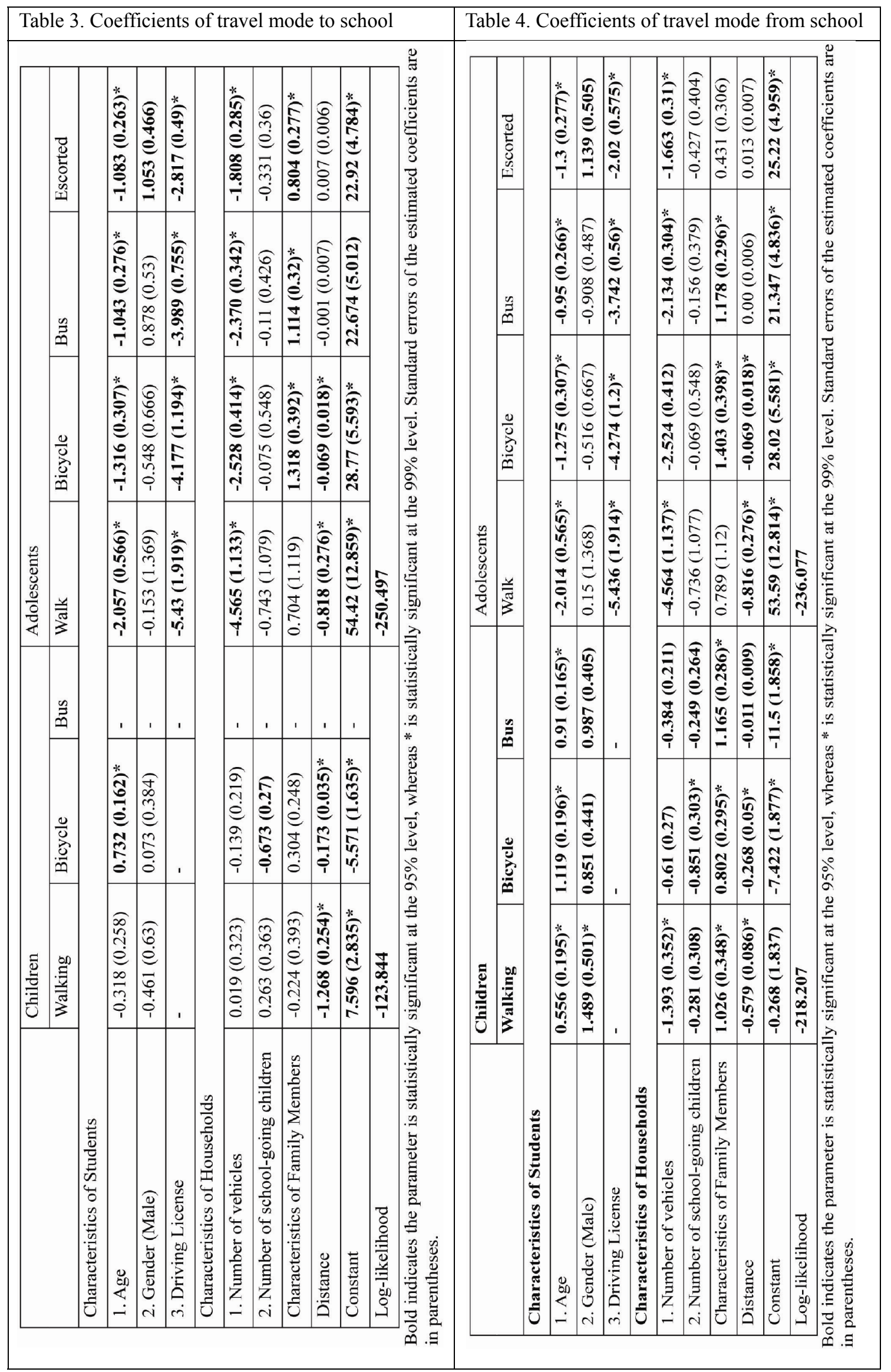




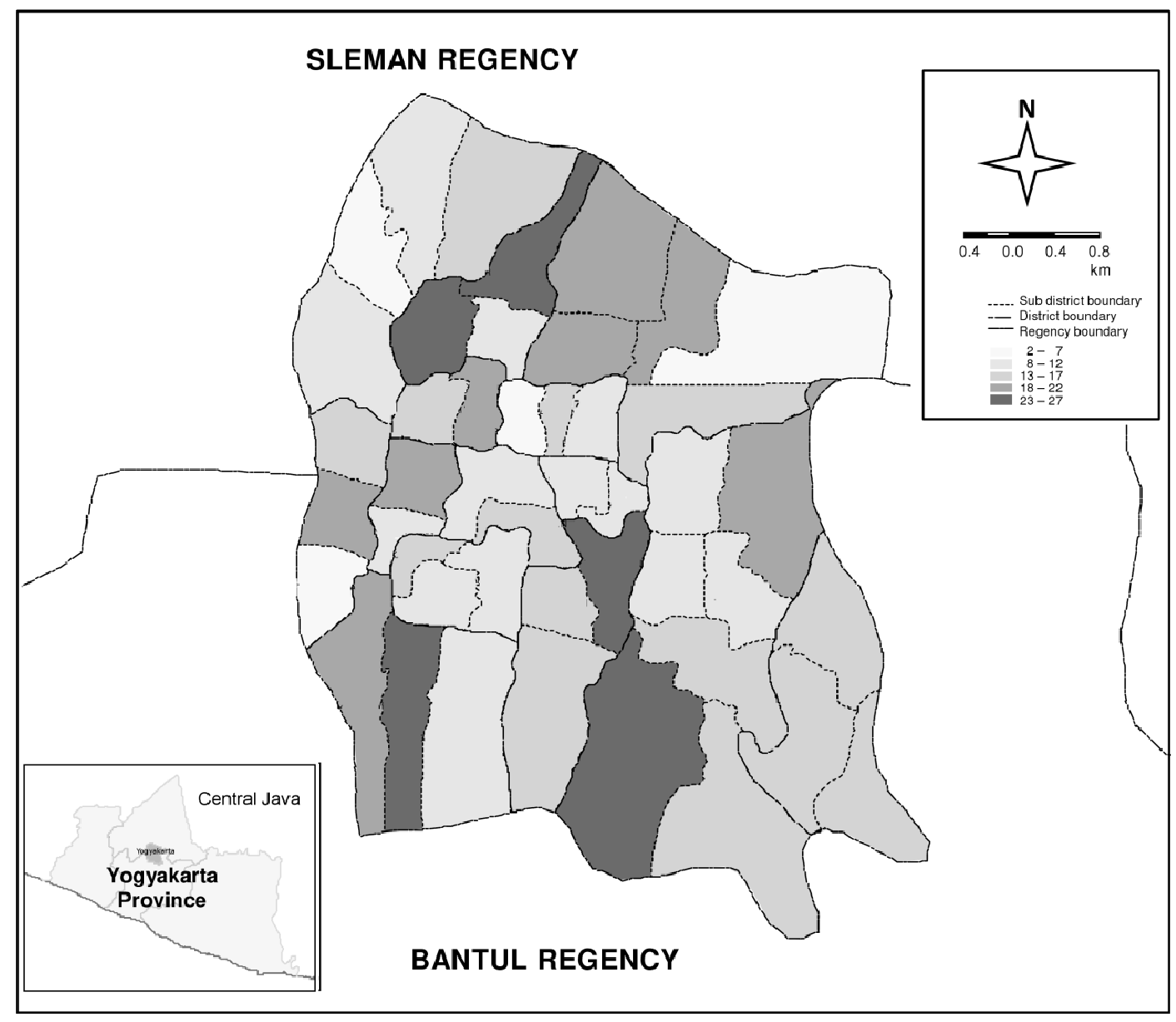

Figure 1. The City of Yogyakarta: Number of School and Its Deployment Location 